\title{
Examples of Mechanisms for Negative Cloud Feedback of Stratocumulus and Stratus in Cloud Parameterizations
}

\author{
Hideaki Kawai \\ Meteorological Research Institute, Japan Meteorological Agency, Tsukuba, Japan
}

\begin{abstract}
Mechanisms of cloud feedback for marine boundary layer clouds in GCMs (General Circulation Models) to the sea surface temperature increase, which can depend on parameterization, were investigated using single column model version of a GCM with two different low cloud schemes.

Both schemes showed negative cloud feedbacks and they were attributed to the increase of the liquid water path (LWP) with the future climate forcing for stratocumulus and stratus. The mechanisms of the LWP increase in the two schemes were investigated respectively through simple numerical experiments. The experimental results imply that in the first scheme, the increase of saturation specific humidity due to the temperature increase in the future climate forcing contributes to the negative cloud feedback through the parameterization determining in-cloud cloud water content (CWC). The results also imply that the increase of latent heat flux in the future climate contributes to increased LWP and hence negative cloud feedback in the other scheme.
\end{abstract}

\section{Introduction}

Global warming simulations by various climate models have exhibited a wide spread in their predicted increases in surface temperature, and this spread has not narrowed even in recent years. It is widely recognized that a large part of this variance arises from a large spread in cloud feedback (e.g., Soden and Held 2006; Soden et al. 2008). It is recently being revealed that a substantial part of the spread in cloud feedback can be attributed to spread in predictions of low clouds, which have large shortwave radiative effect (e.g., Bony et al. 2006). Generally speaking, increases (decreases) in low cloud cover or cloud optical thickness in future climate lead to decreases (increases) in solar insolation reaching the surface, mitigating (enhancing) the temperature increase. However, models do not agree on the magnitude or even the sign of the change of low clouds. Moreover, there are few detailed analyses of the different feedback mechanisms of low clouds attributed to different parameterizations in models.

Against this background, a model intercomparison case CGILS (CFMIP-GCSS Intercomparison of Large-Eddy and Single-Column Models, where CFMIP stands for Cloud Feedback Model Intercomparison Project and GCSS stands for GEWEX (Global Energy and Water Cycle Experiment) Cloud System Study), was designed (Zhang et al. 2012a, 2012b) based on Zhang and Bretherton (2008) to understand in detail the cloud feedback mechanism of marine boundary layer clouds in climate models. In the intercomparison case, three different regimes of marine low-level clouds are simulated: (shallow cumulus, stratocumulus, and stratus) under a control climate forcing and a future climate forcing with a $2 \mathrm{~K}$ increase in sea surface temperature (SST).

The Japan Meteorological Agency (JMA) joined this intercomparison case using the Single-Column Model version of its operational global model, the Global Spectral Model (JMA-GSM). To understand the mechanism of cloud feedback, which can depend on parameterization, two different versions of this Single-Column Model are used and examined. The analysis of cloud

Corresponding author: Hideaki Kawai, Meteorological Research Institute, 1-1 Nagamine, Tsukuba 305-0052, Japan. E-mail: h-kawai@mri-jma.go.jp. (C) 2012, the Meteorological Society of Japan. feedback mechanisms using these models, which are simple but can reproduce realistic amounts of clouds, will also provide basic insight into the cloud feedback mechanisms in more sophisticated models.

\section{Models}

The cloud scheme of JMA-GSM is a Probability Density Function (PDF)-based scheme by Smith (1990) (JMA 2007), but the shape of the PDF is not triangular but uniform and the width corresponds to $20 \%$ of the relative humidity at $850 \mathrm{hPa}$ and decreases downward to the surface. However, marine boundary layer clouds remain generally difficult to simulate realistically with the large-scale atmospheric models used for climate and weather prediction (e.g., Duynkerke and Teixeira 2001; Siebesma et al. 2004). The left-hand panels in Fig. 1 show that this shortcoming clearly appears in JMA-GSM too without any specific treatments for such clouds: the subtropical boundary layer clouds are not represented, and the bias in top-of-atmosphere (TOA) shortwave radiation is huge. Therefore, a simple scheme was developed and added to JMA-GSM to represent boundary layer clouds (Kawai and Inoue 2006, hereafter KI2006); the schemes which represent these clouds are called Sc (stratocumulus) schemes hereafter, although they represent both of boundary layer stratocumulus and stratus.

\subsection{Sc scheme Version 1}

The operational Sc scheme in JMA-GSM (KI2006), hereafter called Version 1 (V1), was originally developed to represent stratocumulus and stratus in models with relatively coarse vertical resolution based on Slingo (1980, 1987).

Three model conditions are necessary to produce these clouds: (1) there is a strong inversion just above the layer, (2) the layer near the surface is not stable (to guarantee existence of a mixed layer), and (3) the scheme is applied only below $940 \mathrm{hPa}$. When these three conditions are met, the following procedures are applied:

(a) Cloud cover is determined as a function of inversion strength.

(b) In-cloud CWC (CWC only over cloudy part in a model grid) is determined, as it is proportional to saturation specific humidity: $q_{c, \text { cld }}=\beta \cdot q_{\text {sat }}$.

(c) Mixing at the cloud top is suppressed; that is, additional mixing at the top of the mixed layer, that is usually used in JMA-GSM to prevent unrealistic formation of boundary layer clouds at the top of the boundary layer, is not applied.

This scheme dramatically improves the representation of subtropical low cloud cover (Fig. 1, middle panels) including its diurnal cycle (KI2006). Onogi et al. (2007, Fig. 9) reported that the bias in the shortwave radiation flux at the surface over subtropical stratocumulus areas in the JRA-25, in which this scheme $\mathrm{V} 1$ is incorporated, is much smaller than that in the ERA-40. It has also been reported that the operational JMA-GSM, which includes Sc scheme V1, is one of the models that best reproduces diurnal variation of low clouds in the GCSS/WGNE (Working Group on Numerical Experimentation) Pacific Cross-section Intercomparison (GPCI, Teixeira et al. 2011, J. Teixeira, personal communication, 2006).

\subsection{Sc scheme Version 2}

Despite its success, V1 produces an inappropriate vertical structure of stratocumulus (KI2006), and it sometimes produces unrealistic low clouds, for example, under extremely dry condi- 

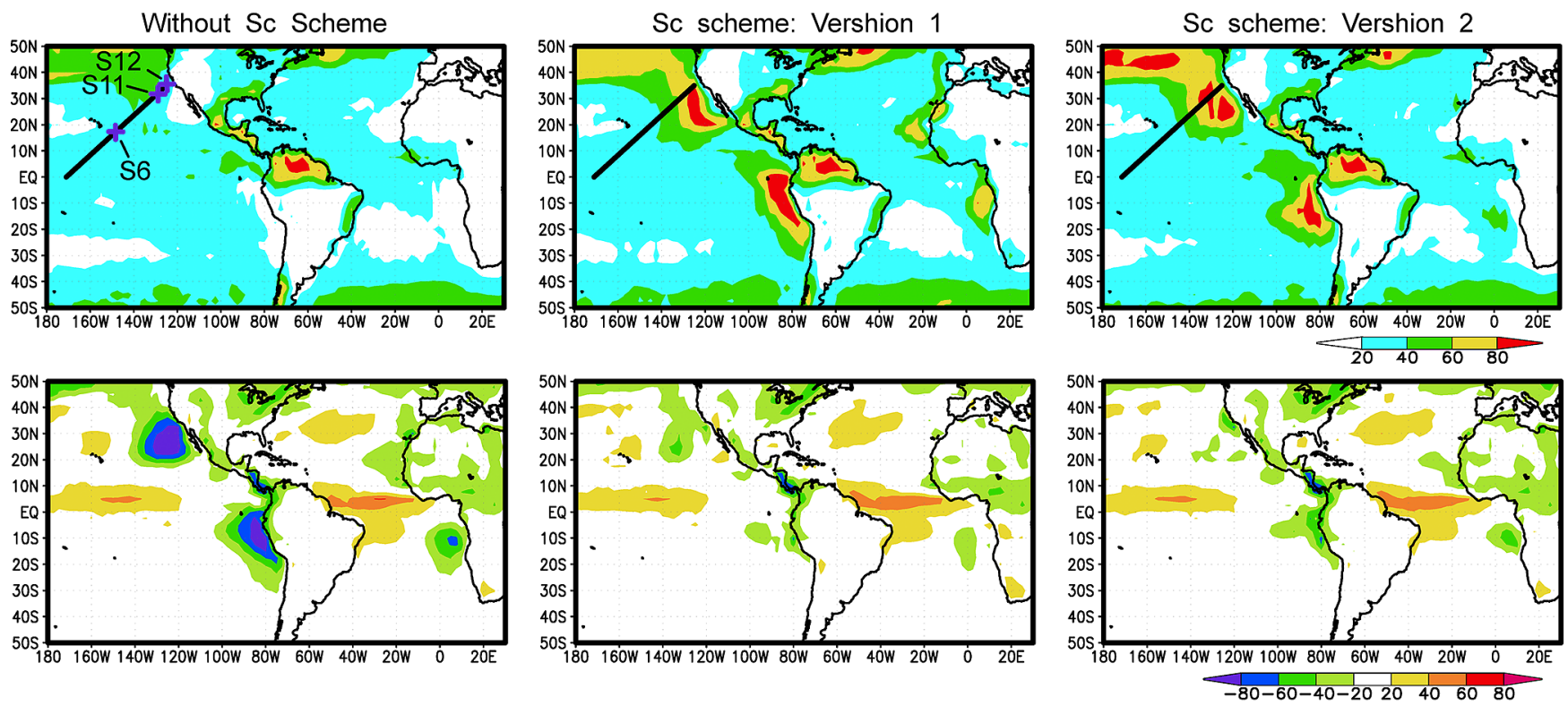

Fig. 1. Top panels: Low (lower than $850 \mathrm{hPa}$ ) cloud cover (\%). Lower panels: Error of TOA upward shortwave flux (W $\mathrm{m}^{-2}$ ). The observation data are from the Earth Radiation Budget Experiment. Using TL159 for July (1987-1989), calculated without an Sc scheme (left panels), with Sc scheme Version 1 (middle), and with Sc scheme Version 2 (right). Black lines in the Pacific are the GPCI line, and locations of S6, S11, and S12 are indicated in the upper left panel.

tions over land. Version 2 (V2) is another simple treatment for boundary layer clouds that is under trial to solve these problems. V2 is even a simpler scheme, but it is confirmed that it performs reasonably well in the current JMA-GSM because of the recent increase in vertical resolution of GSM. In V2, the conditions needed to produce boundary layer clouds are (1) potential temperature difference between $700 \mathrm{hPa}$ and the surface is larger than $20 \mathrm{~K}$ $\left(\theta_{700}-\theta_{\text {surf }}>20 \mathrm{~K}\right)$ and $(2)$ the layer near the surface is not stable. The first condition is the same criterion adopted by the European Centre for Medium-Range Weather Forecasts to distinguish between stratocumulus and shallow convection regimes (ECMWF 2011), based on Klein and Hartmann (1993).

When these two conditions are met, mixing at the top of the cloud layer is completely suppressed to prevent entrainment of dry air in the free atmosphere, because dry air entrainment promotes breakup of the cloud layer (e.g., Lilly 1968; Randall 1980; Kuo and Schubert 1988). Under these conditions, additional mixing at the top of the mixed layer is not applied, as in V1, and the lower limit of vertical diffusivity is made to be almost zero at the top of the cloud layer.

\subsection{Performance of model climatology}

V2 can produce almost the same amount of low cloud cover as V1, and the TOA shortwave bias of both versions is comparably small (Fig. 1). However, the subtropical low clouds in V2 are slightly underestimated in areas adjacent to continents, such as near the coasts of California, Peru, and especially Mauritania and Namibia. Figure 2 shows the vertical structure of low clouds along the GPCI line (location in Fig. 1), in which cloud regimes change from boundary layer stratus at latitude $30-35^{\circ} \mathrm{N}$ to deep convection toward the equator through stratocumulus and shallow cumulus. V1 produces an unrealistic discontinuity of cloud layer height at $30^{\circ} \mathrm{N}$; this transition in V2 looks more natural. This improvement is mainly because the upper limit for application of $\mathrm{Sc}$ scheme, which was needed for V1 (KI2006), could be eliminated in V2. In the case of V2, low clouds can be produced only when the relative humidity is high enough, resulting in prevention of unrealistic cloud occurrence, because the critical relative humidity is determined by the width of the PDF in the PDF scheme for V2. Although V2 shows these improvements, and moreover, V2 is based on physics more than V1, it still has systematic errors, for
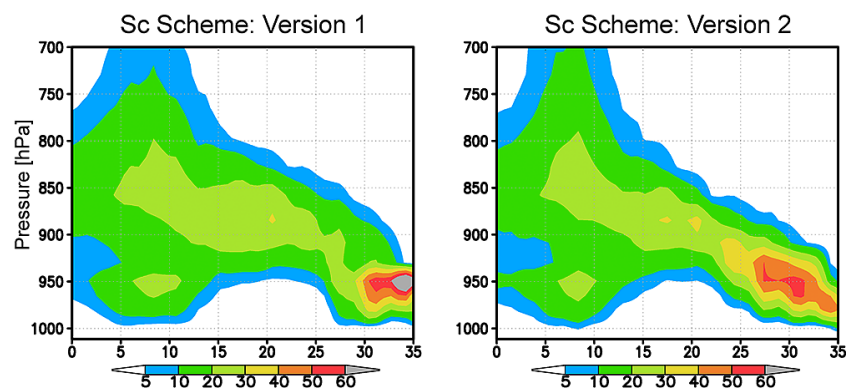

Fig. 2. Vertical cross section of cloud cover (\%) along the GPCI line. Using TL159 for July (1987-1989), calculated with the Sc scheme Version 1 (left) and Version 2 (right).

example, low bias of cloud layer altitude and underestimation of cloud amount in areas adjacent to continents. In order to overcome these shortcomings, at least, sophisticated treatment of cloud top entrainment, inclusion of shallow convection scheme, and further increase of vertical layers in a boundary layer are needed. In addition, the detailed evaluation of PDF width in the PDF scheme, depending on cloud regimes, is also necessary.

\section{Intercomparison case and the basic results}

\subsection{Intercomparison case}

CGILS considers three locations from the GPCI line that correspond respectively to the shallow cumulus regime (S6), stratocumulus regime (S11), and stratus regime (S12) to examine the cloud feedback of marine low clouds. The control climate forcing and the future climate forcing with $2 \mathrm{~K}$ higher SST are given for the simulation in this intercomparison case. The SST, vertical velocity, horizontal wind, and advective tendencies of temperature and specific humidity are given as forcings, while temperature, specific humidity, cloud water content, latent and sensible heat fluxes are calculated by models (as for higher than $600 \mathrm{hPa}$, temperature and specific humidity are nudged to the initial profiles). 

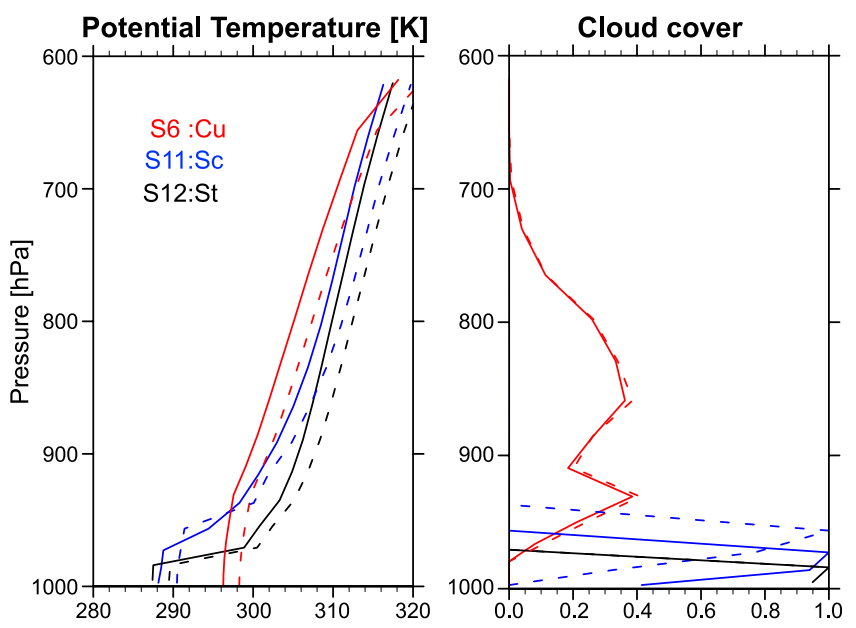

Fig. 3. Vertical profiles of potential temperature (left) and cloud cover (right) for S6 (red), S11 (blue), and S12 (black) using Sc scheme Version 2. Solid lines correspond to control climate forcing, and dashed lines correspond to future climate forcing. Average of integration from 50 days to 100 days (the same for Figs. 4-6).

Single-Column Models in this comparison case are recommended to run for 100 days under a constant forcing to obtain an equilibrium state. See Zhang et al. (2012b, 2012a, 2011) for the details of the case.

\subsection{Basic results}

Figure 3 shows the vertical profiles of potential temperature and cloud cover at S6, S11, and S12 using Sc scheme V2. At S6, the cloud layer was relatively high, representing shallow convection. Cloud cover was $100 \%$ at S11 and S12, and the heights of the cloud layer and cloud top inversion were the lowest at S12 among three regimes. The cloud layer at S11 was raised by one model layer under the future climate forcing. It is reported that this similar rise occurs at S11 in Single-Column Model simulations of some CGILS participants (Zhang et al. 2012a).

Both V1 and V2 of JMA-GSM Single-Column Model produced negative cloud feedback for all three cloud regimes under the future climate forcing (Fig. 4, right panel). The cloud cover remained at $100 \%$ for both control and future climate forcings at S11 and S12 with either V1 or V2 (see Fig. 3 for V2). Consequently, the changes in cloud cover for them were zero (Fig. 4, left panel). The liquid water path (LWP) increased under future climate forcing for all cloud regimes with either V1 or V2 (Fig. 4, middle panel). Therefore, the negative cloud feedback is a consequence of the increase of LWP at S11 and S12.

\section{Mechanisms of increase of LWP}

To understand the mechanisms of the increase of LWP under the future climate forcing, simple numerical experiments were performed for each version of the Sc schemes, because the mechanisms could differ in the two parameterizations. The results at S11 and S12 are reviewed in this paper, where the clouds are produced by the Sc schemes and the mechanisms are relatively simple compared with those at $\mathrm{S} 6$.

\subsection{Mechanism in Sc scheme Version 1}

In Sc scheme V1, in-cloud CWC is determined by the equation $q_{c, \text { cld }}=\beta \cdot q_{\text {sat }}$ as described in Section 2, based on a simple concept that stratiform clouds can maintain cloud water/ice inside whose content corresponds to a small percent of the saturation specific humidity. When the temperature is increased by $2 \mathrm{~K}$, the saturation specific humidity is increased by about $13 \%$. Therefore, as a simple test, the right-hand side of the equation was multiplied by 1.13 using the control climate forcing.

When the factor was multiplied under control climate forcing (Fig. 5), the resulting changes of LWP and cloud radiative effect (CRE) were comparable to those with future climate forcing, although these changes are not quite identical quantitatively. This result implies that the increase of saturation specific humidity in the future climate contributes to the negative cloud feedback through the in-cloud CWC equation in scheme V1. The same mechanism may also cause negative cloud feedback in those models where the similar equation is used to determine in-cloud CWC, such as diagnostic cloud cover schemes based on relative humidity (e.g., Slingo 1980, 1987) or other parameters (e.g., Teixeira and Hogan 2002).

\subsection{Mechanism in Sc scheme Version 2}

In Sc scheme V2, CWC is determined through the Smith (1990) PDF scheme as a balance of many physical processes. However, the influence of the change of mixing at the cloud top
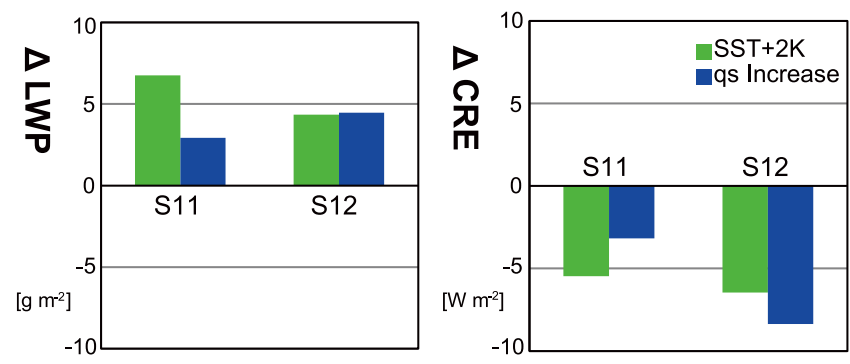

Fig. 5. Changes of liquid water path (left) and cloud radiative effect (right) between the control climate and future climate forcings (green), and between the default parameterization and one with a modified calculation of in-cloud CWC (blue). Results are shown for S11 and S12 using Sc scheme Version 1.
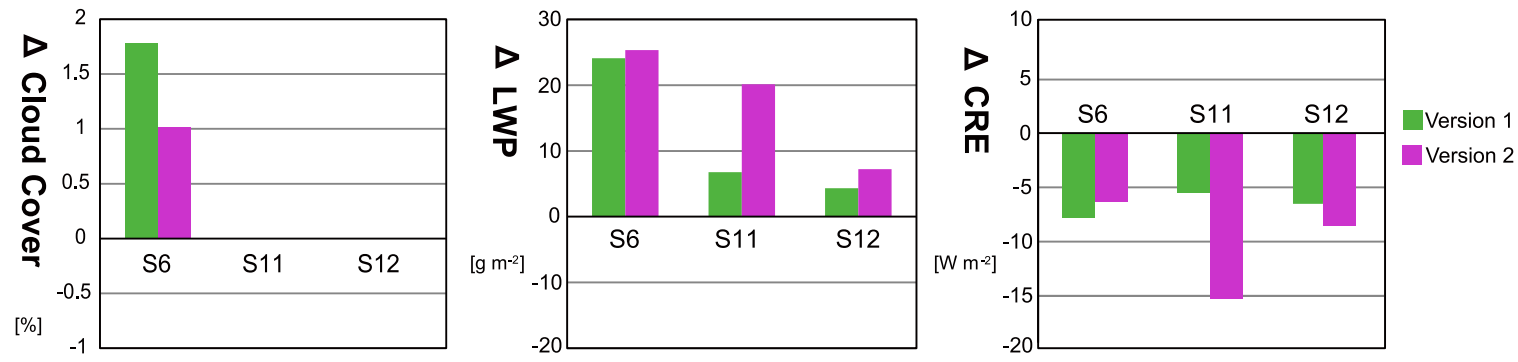

Fig. 4. Changes of cloud cover (left), liquid water path (middle), and cloud radiative effect (CRE, right) between control climate and future climate forcings. CRE is defined as a component of net radiation flux affected by clouds at the top of the atmosphere where positive sign corresponds to downward. Results are shown for S6, S11, and S12 using Sc scheme Version 1 (green) and Version 2 (purple). 

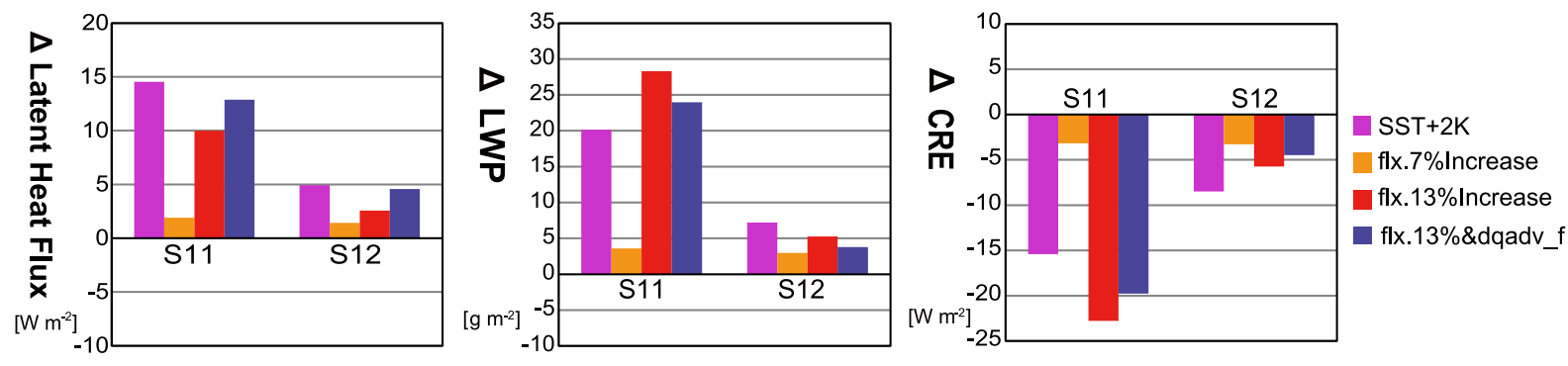

Fig. 6. Change of latent heat flux (left), liquid water path (middle), and cloud radiative effect (right) between the control climate and future climate forcings (purple), and between the default parameterization and one in which the calculated latent heat flux in the surface flux parameterization is increased by $7 \%$ (orange) or $13 \%$ (red). Impact of the combination of $13 \%$ flux increase and a change of specific humidity advection forcing is also shown (dark blue). Results are for S11 and S12 using Sc scheme Version 2.

can be ignored in this scheme because the mixing is set to zero, as described in Section 2. The change of shallow convection can be also ignored here because a convection scheme didn't work at S11 or S12 in the simulation. In this case, the balance of processes in this parameterization can be simplified as follows. There is positive feedback between $\mathrm{CWC}$, and processes of radiative cooling at the cloud top and water vapor transport by turbulence. On the other hand, there is negative feedback between CWC and a conversion process of CWC to precipitation. The equilibrium CWC can be determined by a balance between these two feedback processes. In the simulation, the latent heat flux increased from 62.3 to $67.3 \mathrm{~W} \mathrm{~m}^{-2}$, LWP increased from 48.7 to $55.9 \mathrm{~g} \mathrm{~m}^{-2}$, and precipitation increased from 0.316 to $0.390 \mathrm{~mm}^{-1 a y}{ }^{-1}$ for $\mathrm{V} 2$ with the future climate forcing. Based on this concept, I performed a simple test of increasing the latent heat flux. The latent heat flux is calculated in the model by the equation

$$
Q_{E}=\rho L C_{h}\left|U_{1}\right|\left(q_{s}-q_{1}\right),
$$

where $\rho$ is air density, $L$ is heat of evaporation, $C_{h}$ is the coefficient, $U$ is horizontal wind speed, $q$ is specific humidity, and subscripts 1 and $s$ indicate variables at the lowest model level and the ground surface, respectively. The latent heat flux calculated by this equation increases in the future climate if the relative humidity is not changed in the future climate, as is often assumed. When the temperature is increased by $2 \mathrm{~K}$, the latent heat flux is increased by about $13 \%$ through this equation under unchanged relative humidity. Therefore, as a simple experiment, the flux calculated by the equation was multiplied by 1.13 in the model for the control climate forcing simulation and another experiment with the flux multiplied by 1.07 was performed as a sensitivity experiment.

In addition, the forcing of specific humidity advection in this comparison case is negative in a mixed layer, and the value is more negative in the future climate. Therefore, the impact of this change of specific humidity advection forcing was also tested.

When the latent heat flux was increased by 7\% (Fig. 6), the changes of latent heat flux, LWP, and CRE were much smaller than the changes with future climate forcing. However, the changes resulting from a $13 \%$ increase of latent heat flux were comparable to the changes with future climate forcing. These results imply that the increase of latent heat flux in the future climate contributes to the increase of LWP and hence the negative cloud feedback. It is worth noting that the changes at S11 resulting from a $13 \%$ increase are much larger than the changes from a $7 \%$ increase and this large difference is caused by a change in vertical structure of the cloud layer. The cloud layer at S11 is lifted by one model vertical level with future climate forcing, as shown in Fig. 3 (This rise happened only in V2 and not in V1). The same discrete lift occurred in the simulation with a $13 \%$ increase of latent heat flux and resulted in a steplike transition in the balance among latent heat flux, LWP, and CRE. These results are robust because further sensitivity tests showed that the increase of this factor gives monotonic increase of the changes of these values. The figure also shows that greater drying forcing related to the specific humidity advection in the future climate contributes to reduce LWP and CRE and increase latent heat flux to some extent. It is totally understandable that a larger sink term of moisture in a boundary layer decreases LWP and increases latent heat flux.

\section{Summary}

In order to understand the mechanism of cloud feedback of marine boundary layer clouds in GCMs, which can depend on parameterization, results of a CGILS model intercomparison case using two different Sc schemes in JMA-GSM Single-Column Model were investigated. Both of these schemes reproduced marine boundary layer clouds reasonably well. Both showed negative cloud feedback, attributed to the increase of LWP with the future climate forcing for all boundary layer cloud regimes. The mechanisms underlying this increase of LWP in the two versions were then investigated for S11 (stratocumulus) and S12 (stratus).

The results imply that the increase of saturation specific humidity $q_{s a t}$ due to the temperature increase in the future climate contributes to the negative cloud feedback in Sc scheme Version 1 through the equation governing in-cloud CWC. This mechanism can work not only for models using this kind of equation to determine in-cloud CWC (e.g., relative humidity-based diagnostic cloud schemes), but also for models employing critical CWC which is proportional to $q_{\text {sat }}$, for example, to determine the threshold of conversion of CWC to precipitation or the upper limit of cloud water detrainment from convection.

In the case of Sc scheme Version 2, the LWP increase arises from a shift of equilibrium LWP that is probably determined by a balance among radiative cooling at the cloud top, water vapor transport by turbulence, and the conversion of CWC to precipitation. The result implies that the increase of latent heat flux in the future climate contributes to the increase of LWP and hence the negative cloud feedback. This feedback mechanism can happen in models in which the balance among these three physical processes is what mainly determines the LWP.

Studies of mechanisms of cloud feedback linked intrinsically with parameterizations in models have begun only recently (e.g., CGILS), and this study showed simple examples of such mechanisms. These mechanisms can partly operate in more sophisticated models, and analysis of the feedbacks using relatively simple models may help in understanding the complicated cloud feedback mechanisms in cloud parameterizations.

\section{Acknowledgements}

This study was supported by "Program for Risk Information on Climate Change (SOUSEI)" of the Ministry of Education, Culture, Sports, Science, and Technology (MEXT) of Japan. I acknowledge the anonymous reviewers for their constructive and insightful comments. The Single-Column Model version of JMA-GSM was developed mainly by Hiroto Kitagawa and Takashi Nakamura during their tenure at the Numerical Prediction 
Division of JMA. The figures in this paper were edited by Rikako Matsumoto.

\section{References}

Bony, S., R. Colman, V. M. Kattsov, R. P. Allan, C. S. Bretherton, J. L. Dufresne, A. Hall, S. Hallegatte, M. M. Holland, W. Ingram, D. A. Randall, B. J. Soden, G. Tselioudis, and M. J. Webb, 2006: How Well Do We Understand and Evaluate Climate Change Feedback Processes? J. Climate, 19, 34453482 .

Duynkerke, P. G., and J. Teixeira, 2001: Comparison of the ECMWF Reanalysis with FIRE I Observations: Diurnal Variation of Marine Stratocumulus. J. Climate, 14, 14661478.

ECMWF, 2011: IFS Documentation Cy37r2. ECMWF, Part IV: Physical Processes, [Available online at http://www.ecmwf. int/research/ifsdocs/CY37r2/IFSPart4.pdf.]

JMA, 2007: Outline of the operational numerical weather prediction at the Japan Meteorological Agency. Japan Meteorological Agency, $196 \mathrm{pp}$.

Kawai, H., and T. Inoue, 2006: A simple parameterization scheme for subtropical marine stratocumulus. SOLA, 2, 17-20.

Klein, S. A., and D. L. Hartmann, 1993: The seasonal cycle of low stratiform clouds. J. Climate, 6, 1587-1606.

Kuo, H.-C., and W. H. Schubert, 1988: Stability of cloud-topped boundary layer. Quart. J. Roy. Meteor. Soc., 114, 915-944.

Lilly, D. K., 1968: Models of cloud-topped mixed layers under a strong inversion. Quart. J. Roy. Meteor. Soc., 94, 292-309.

Onogi, K., and co-authors, 2007: The JRA-25 Reanalysis. J. Meteor. Soc. Japan, 85, 369-432.

Randall, D. A., 1980: Conditional Instability of the First Kind Upside-Down. J. Atmos. Sci., 37, 125-130.

Siebesma, A. P., and co-authors, 2004: Cloud representation in general-circulation models over the northern Pacific Ocean: A EUROCS intercomparison study. Quart. J. Roy. Meteor. Soc., 130, 3245-3267.

Slingo, J. M., 1980: A cloud parameterization scheme derived from GATE data for use with a numerical model. Quart. J. Roy. Meteor. Soc., 106, 747-770.
Slingo, J. M., 1987: The development and verification of a cloud prediction scheme in the ECMWF model. Quart. J. Roy. Meteor. Soc., 113, 899-927.

Smith, R. N. B., 1990: A scheme for predicting layer clouds and their water content in a general circulation model. Quart. J. Roy. Meteor. Soc., 116, 435-460.

Soden, B. J., and I. M. Held, 2006: An Assessment of Climate Feedbacks in Coupled Ocean-Atmosphere Models. J. Climate, 19, 3354-3360.

Soden, B. J., I. M. Held, R. Colman, K. M. Shell, J. T. Kiehl, C. A. Shields, 2008: Quantifying Climate Feedbacks Using Radiative Kernels. J. Climate, 21, 3504-3520.

Teixeira, J., and T. F. Hogan, 2002: Boundary Layer Clouds in a Global Atmospheric Model: Simple Cloud Cover Parameterizations. J. Climate, 15, 1261-1276.

Teixeira, J., and co-authors, 2011: Tropical and Subtropical Cloud Transitions in Weather and Climate Prediction Models: The GCSS/WGNE Pacific Cross-Section Intercomparison (GPCI). J. Climate, 24, 5223-5256.

Zhang, M., and C. Bretherton, 2008: Mechanisms of Low CloudClimate Feedback in Idealized Single-Column Simulations with the Community Atmospheric Model, Version 3 (CAM3). J. Climate, 21, 4859-4878.

Zhang, M., C. Bretherton, A. Lock, M. Webb, M. Khairoutdinov, and A. Cheng, 2011: CGILS (CFMIP-GCSS Intercomparison of Large-Eddy and Single-Column Models). (Available online at http://atmgcm.msrc.sunysb.edu/cfmip_figs/Case_ specification.html)

Zhang et al., 2012a: CGILS: Understanding the Physical Mechanisms of Low Cloud Feedbacks in Climate Models. Bull. Amer. Meteor. Soc., Submitted.

Zhang, M., C. S. Bretherton, P. N. Blossey, S. Bony, F. Brient, and J.-C. Golaz, 2012b: The CGILS Experimental Design to Investigate Low Cloud Feedbacks in General Circulation Models by Using Single-Column and Large-Eddy Simulation Models. J. Adv. Model. Earth Syst., Submitted. (Available online at http://www.atmos.washington.edu/ bloss/papers/ CGILS_Forcing_submitted.pdf).

Manuscript received 5 September 2012, accepted 22 October 2012 SOLA: http://www.jstage.jst.go.jp/browse/sola 